\title{
REGULACIÓN ECONÓMICA Y MERCADO EN EL SECTOR DE LAS TELECOMUNICACIONES. TELEFÓNICA: 1945-1965 *
}

\author{
ÁNGEL CALVO CALVO

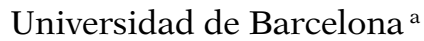

Economic Regulation and the Market in the Telecommunication Sector. Telefónica: 1945-1965

\begin{abstract}
This article analyses the impact of market forces and regulation in the Spanish telephone sector. It aims to explore the combined effects of the intersection between regulation of the monopoly, economic policy and entrepreneurial strategies, and hypothesizes that the regulation had a decisive influence on the development of the networks and services. Chronologically, the study covers the two decades of the transition from autarky to the Stabilization and Development Plans. In its double supply-demand approach, the article quantifies investment as an expression of supply and reviews the ground rules within which these two market forces developed. Finally, it examines the situation of shortages that the intervention created, and explains the intervention in prices from the perspective of the trade-off between its use as an element of stabilization and the bargaining power of the sector. The conclusions reflect the impact of the regulation and highlight its more complex aspects.
\end{abstract}

Keywords: Telefónica, telecommunications, economic regulation, tariffs JEL Classification: D4, L1, L9, N7

* Received 03/18/2008. Accepted 05/14/2009. Agradezco a la Dirección General de Investigación la financiación del proyecto ECO2008-00398/ECON, vinculado al Centre A. de Capmany (UB). Debo el acceso a los archivos de Telefónica a su dirección y a N. Serra, ex vicepresidente del Gobierno, así como a diferentes cargos y personal de la misma (A. Alonso y R. Sánchez de Lerín, sucesivos secretarios del Consejo de Administración; Javier Nadal, vicepresidente ejecutivo de Fundación Telefónica; C. Barbé, M. ${ }^{a}$ V. Cerezo y B. Jiménez). Vaya también mi gratitud por sus comentarios y sugerencias a las siguientes personas: F. Antolín, P. Fernández y D. Tirado; asistentes a las sesiones del Congreso de ICOHTEC (Copenhague, 2007); del II Col-loqui d'Història de la Tècnica, ETSEIBUPC (Barcelona, 2007) y de las IX y X Trobades de la SCHCT (Girona, 2008; Lleida, 2009); evaluadores anónimos. Por descontado, los posibles errores son de mi entera responsabilidad.

a Facultad de Economía y Empresa. Departamento de Historia e Instituciones Económicas. Avda. Diagonal, 696.08034 Barcelona. angel.calvo@ub.edu. 


\section{RESUMEN}

Este artículo analiza el juego de las fuerzas de regulación y mercado en el sector telefónico español. Su objetivo es explorar los efectos combinados de la intersección entre regulación del monopolio, política económica y estrategias empresariales, estableciendo como hipótesis que las peculiaridades de la regulación incidieron decisivamente en el desarrollo de las redes y de los servicios. Cronológicamente, el estudio abarca las dos décadas comprendidas por la transición de la autarquía a los Planes de Estabilización y Desarrollo. En su doble aproximación oferta-demanda, el artículo cuantifica la inversión como expresión de la oferta y repasa las reglas del juego en las que se mueven esas dos fuerzas del mercado. Finalmente, estudia la situación de escasez a la que conduce esa intervención y explica la intervención en precios desde la óptica del balance entre el uso de la misma como elemento de política económica (estabilización) y el poder de negociación del sector. Las conclusiones se hacen eco del impacto de la regulación, subrayando sus aspectos complejos.

Palabras clave: Telefónica, telecomunicaciones, regulación económica, tarifas

\section{INTRODUCCIÓN}

Las telecomunicaciones, industrias de red generadoras de externalidades ${ }^{1}$, viven una edad de oro como pilares que son de la nueva economía de la información y del conocimiento ${ }^{2}$. Lugar tan sobresaliente apenas les ha dado cabida en la historia económica española, sea en su vertiente de industria o en la de servicio ${ }^{3}$. Resarcida ya generosamente la deuda de la disciplina con la producción de electricidad, es hora de afrontar este nuevo reto que, a no dudarlo, se trocará en eje privilegiado de avance, a tenor de las nuevas preguntas que la aceleración del cambio en las telecomunicaciones formula a los científicos sociales ${ }^{4}$.

Porción sustancial de estos interrogantes atañen a la intersección entre regulación y monopolios, objeto de este trabajo, centrado en el caso español. Tres son los rasgos singulares que lo hacen atractivo para los estudiosos. Frente al llamado modelo PTT o SOE (State Owned Enterprise), amplia-

${ }^{1}$ David (1992, pp. 103-105); Krantz (2000, pp. 5-29); Röller y Wavermann (2001, pp. 909-923); Herranz (2007).

2 Mokyr (1997, pp. 31-43); New (2000); Dudley (1999, pp. 595-619).

3 La escasa atención prestada a los servicios ha sido subrayada por Cuadrado (2001, pp. 357364) y Carreras (2007, pp. 25-38), quien se refiere a ellos como «molestia analítica» en nuestra disciplina.

${ }^{4}$ David (2006) y Noll (2000). 
mente generalizado en Europa, público — tan sólo el 15,8 por cien de los teléfonos existentes eran explotados por compañías privadas- e incluso incardinado en un departamento nutrido con presupuesto estatal, en España el teléfono era un monopolio con mayoría de capital privado. A su vez, la pauta española añadía una desintegración horizontal, frente al modelo europeo, que reunía las secciones de correos, telégrafos y teléfonos en un solo organismo. La tercera característica diferencial, no exenta de ciertos matices, gravitaba en una integración vertical atenuada entre el servicio y la industria manufacturera, vía participación de CTNE en el capital de Standard Eléctrica y contratos de suministro en exclusiva firmados entre ambas, a la caza de economía y eficiencia ${ }^{5}$. Aparte de ello, tampoco fue inocente la relación entre el sector y la Administración española, muy distante de la existente hoy entre el regulador independiente (CMT o la Secretaría de Estado en lo que le compete) y las compañías operadoras. Durante la época de monopolio, los papeles no estaban claramente separados, situación impuesta por el contrato de 1946 entre el Estado y la CTNE, auténtico marco regulador reforzado por la figura del delegado del Gobierno en la compañía telefónica. En otras palabras, se trataba de una relación compleja, muy distante de una situación en la que los intereses en juego fueran los de una empresa totalmente privada y autónoma. Ahora bien, a diferencia de Europa, España tenía un Estado carente de respaldo democrático, que, en lugar de alinearse con la práctica europea, basada en la nacionalización con elevación de impuestos y precios por encima de los costes para subvencionar el servicio postal deficitario, estableció un control sobre el precio de los servicios por imperativos ideológicos, de política económica —contención de salarios-y de búsqueda de legitimación social. Por si fuera poco, frente a una Europa democrática y aupada en una edad de oro, el franquismo se vio sumido durante sus primeros años en un aislamiento internacional y la población en el hambre y la miseria ${ }^{6}$.

5 Entre un sinfín de referencias, véase Majone (1996, p. 20), Noam (1990, pp. 461-462), Hayward (1995, p. 243), Brock (1995, p. 179), Lafont y Tirole (2001, p. 3) y ATT (1914, p. 12). Lo común en el modelo PTT era el monopolio legal —diferente del monopolio de facto-, si bien las formas podían variar de un país a otro. Pese a la independencia formal otorgada por ley en 1961, el presupuesto y las tarifas del British Post Office continuaron bajo el control del Tesoro y el Parlamento. Respecto a la integración vertical, mientras en Francia existió un cuasi monopolio de suministro de equipo hasta el inicio de la década de 1960, Gran Bretaña rompió con sus proveedores habituales de equipo de transmisión (1946), cable telefónico (1952), baterías (1956) y bobinas de carga (1963). Véase Hardy y otros (2002, p. 7); Foreman-Peck y Muller (1988, p. 138); Hills (1984, pp. 114 y 124-125).

${ }^{6}$ Implicaciones técnicas de la evolución de las tarifas en Europa: Chapuis y Amos (2005, p. 340) y CCITT (1964). En el modelo PTT, la intervención gubernamental estaba sometida a control parlamentario: Hulsink (2002, pp. 11 y 77). Aquí se roza el territorio de la pujante new political economy: Acemoglu et al. (2006, pp. 6-9), Shleifer y Vishny (1998) y López (2001, p. 160). En Europa, estaba bastante extendida la práctica de tarifas no lineales o subsidios cruzados entre tarifas de larga y corta distancia para compensar la falta de rendimiento de las llamadas locales. En Alemania, la diferencia entre el coste y los ingresos por llamadas locales fue de 2,9 millones de marcos, muy por debajo 
Así pues, las páginas que siguen abordan el análisis del juego de las fuerzas de regulación y mercado en el sector telefónico español. Su objetivo es explorar los efectos combinados de la intersección entre regulación del monopolio, política económica y estrategias empresariales, estableciendo como hipótesis que las peculiaridades de la regulación incidieron decisivamente en el desarrollo de las redes y de los servicios. Cronológicamente, el estudio comprende desde 1945 hasta 1965, dos décadas dispares que delimitan la transición de la autarquía a los Planes de Estabilización y Desarrollo, a la vez que el arranque de la gran expansión del teléfono. Respecto a su estructura, el estudio aborda en primer lugar la demanda, desagregándola en sus diversas magnitudes, y la oferta. Tras cuantificar la inversión como expresión de la oferta, revisa las reglas del juego en las que se mueven esas dos fuerzas del mercado. Finalmente, examina la situación de escasez a la que conduce la intervención estatal y explica la intervención en precios desde la óptica del balance entre el uso de la misma como elemento de política económica (estabilización) y el poder de negociación del sector. Las conclusiones recogen los resultados de la regulación, subrayando sus aspectos contradictorios, que se resumen en un importante crecimiento de la red, sin conseguir recortar distancias respecto al grupo de países europeos con mejor servicio. Otros aspectos negativos, especialmente la pervivencia de listas de espera, reflejo de una demanda insatisfecha, y las líneas compartidas, no fueron privativas de España aunque sí lo fue la magnitud con que se plasmaron.

\section{LAS FUERZAS DEL MERCADO: DEMANDA Y OFERTA}

Antes de adentrarnos en las cuestiones que son objeto central del estudio, conviene referirse a los aspectos más básicos, conocidos gracias a notables series estadísticas que expresan la evolución del teléfono en España (Gómez Mendoza en Carreras y Tafunell, 2005). El tamaño de la red experimentó un auge, reflejado en un crecimiento importante de las instalaciones. Muestra de la velocidad de la expansión, mientras el primer millón de teléfonos hubo de esperar sesenta años, en solo siete se rebasó el segundo millón. Sin abandonar ese elemento técnico, los 433.738 teléfonos existentes en 1945 se habían multiplicado por un factor de 3,4 trece años después y por 6,4 al cabo de dos décadas. Algo semejante puede decirse si consideramos las líneas en servicio, en este caso con multiplicadores ligeramente inferiores - 3,16 y 5,67- en las mismas fechas. Para verlo desde otro componente técnico más refinado, el número de circuitos interurbanos casi se quintuplicó y los

de los 492,7 por llamadas interurbanas: Deloraine (1969, p. 6). Las especificidades del sector lo hacen difícilmente encajable en los dos modelos vigentes (captura del estado o instrumentación recíproca): Pueyo (2008). Regulación económica: (Kahn, 1988), Baudrier (2001), Bel (comp.) (1996) y Stern y Trillas (2001). 
394.000 kilómetros de circuito de 1946 se triplicaron sobradamente en 1958, lo que suponía un promedio anual de 63.000 kilómetros, con puntas superiores a los 200.000 kilómetros en 1957-1958. Estos dos años sumaron más cantidad de circuitos que la totalidad instalada hasta ese momento. En perspectiva comparada, la red de CTNE superaba en 186.060 kilómetros a la red telegráfica pública en $1962^{7}$. Por otro lado, el incremento cuantitativo de aparatos fue acompañado de la expansión geográfica, ya que el número de poblaciones provistas de teléfono se duplicó con creces.

\section{GRÁFICO 1}

EXPANSIÓN DEL TELÉFONO EN ESPAÑA, 1945-1965

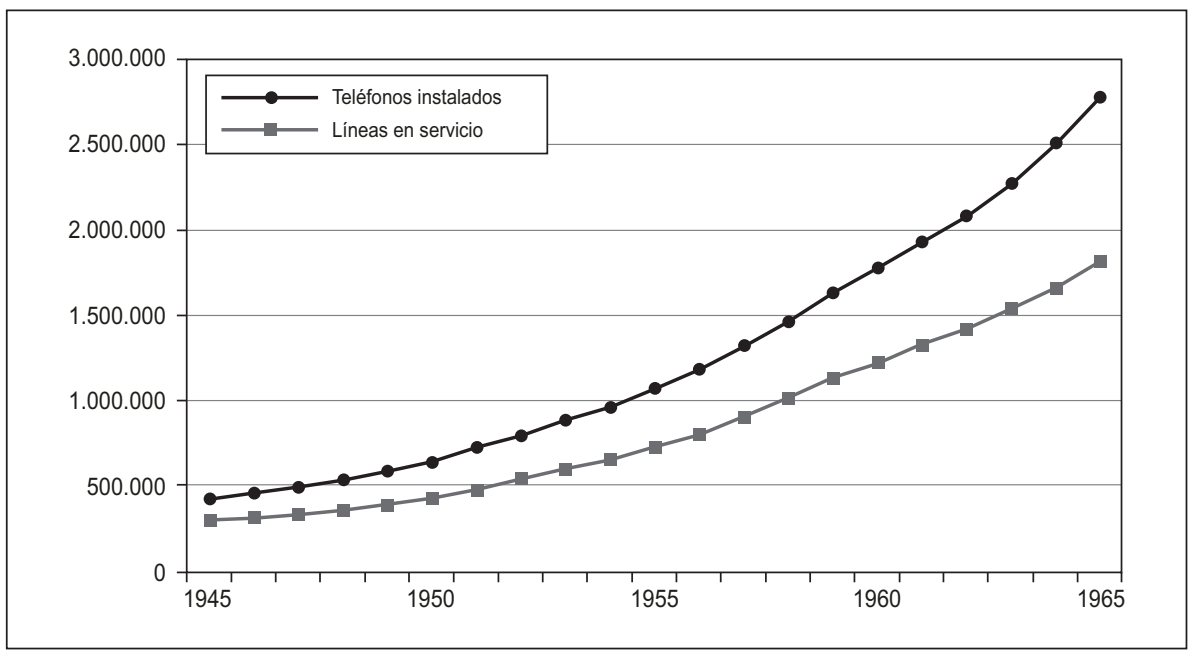

Fuente: Elaborado a partir de CTNE, Actas del Consejo y Memoria(s).

Incurriríamos en imperdonable negligencia si olvidásemos otro rasgo nada desdeñable: la concentración geográfica de las infraestructuras, responsable de una auténtica brecha territorial. Buena muestra de una disparidad en el acceso al servicio, en la fecha final del periodo, si la teledensidad media nacional o número de teléfonos por cien habitantes era de 8,67, por debajo de 4 estaban Extremadura, Castilla-La Mancha, tres andaluzas (Almería, Huelva y Jaén), tres castellano-leonesas (Ávila, Soria y Zamora), dos gallegas (Lugo y Orense) y una aragonesa (Teruel). En el extremo opuesto, los valores de Barcelona, Madrid y Vizcaya estaban por encima de

${ }^{7}$ Libros de Actas del Consejo de Administración (LACA), 30 de septiembre de 1958, 20 de junio y 26 de septiembre de 1962. Dada la instalación creciente de cables coaxiales, más que la longitud de las líneas es el total de circuitos lo que marca la capacidad. 
12 teléfonos por cien habitantes. Se trataba de un efecto combinado de diversos factores, entre los que descuella el nivel de renta, pero también el grado de urbanización y de industrialización ${ }^{8}$.

Si la expansión del teléfono deja poco lugar a la discusión, los rasgos de la demanda han escapado a una observación más atenta. En cabeza figura la baja tasa de utilización del teléfono, en consonancia con la reducida capacidad general de consumo de la población española ${ }^{9}$. Como prueba, tan solo el 30 por cien de los abonados llegaba a los 200 pasos gratuitos a que daba derecho la cuota mensual de abono, mientras que la mitad de los usuarios efectuaba un promedio de tan solo sesenta llamadas mensuales. Sin embargo, el grupo con mayor intensidad de uso, siendo numéricamente más reducido, sumaba el 84,7 por cien del volumen total de tráfico registrado, en cifras de 1958. Abundando en la reducida eficiencia, no pocas líneas sólo se utilizaban durante doce minutos al día. Pero eso no era todo. Aparte de escasa, la intensidad de uso era tendencialmente decreciente, reflejo sin duda de la incorporación de usuarios de rentas bajas. En términos comparativos y utilizando como medida las llamadas por habitante, España estaba muy alejada del grupo de cabeza, formado por los países nórdicos (Dinamarca, Suecia y Noruega), y a respetable trecho de las grandes potencias industriales, lo que equivale a situarla entre los países rezagados, como Grecia y Portugal ${ }^{10}$.

El conocimiento más exacto de algunas redes revela peculiaridades en la pauta de los grandes núcleos urbanos de Madrid y Barcelona, que concentraban una notable proporción de la demanda, y, por tanto, aporta a los rasgos generales la incidencia de la escala. Tan sólo la quinta parte de los abonados de ambas ciudades podían ser incluidos en el grupo de fuertes consumidores en 1957, pero el promedio de recaudación por abonado quintuplicaba con generosidad el del conjunto de abonados. A ello cabe añadir, en el caso de Madrid, que las conferencias tenían una duración media ligeramente superior a los dos minutos por la misma época ${ }^{11}$.

A la particularidad de los grandes núcleos hay que añadir la excepcionalidad de Madrid, punto de confluencia de las rutas principales dentro de un trazado radial. Debido a esta razón, el enorme tráfico de tránsito sobrecar-

${ }^{8}$ En 1966, casi la mitad del personal de teléfonos prestaba servicio en Cataluña y el centro: Anuario Estadístico Telefónico (AET) (1975, pp. 32-33, 56, 191-192). Baleares y Barcelona superaban ampliamente la renta media nacional en 1964; Galicia y Castilla no la alcanzaban. Madrid era un caso especial, no vinculado al factor renta, ligeramente por debajo de la media nacional. Frente al término de tasa de penetración se ha adoptado el de teledensidad o número de teléfonos por cien habitantes, preferido por PNUD como indicador del nivel de acceso de un país a las telecomunicaciones.

9 A excepción del breve lapso 1944-1947, la participación del consumo privado en la renta siguió una trayectoria descendente: Carreras y Tafunell (2005, p. 180).

${ }^{10}$ World's Telephone ATT; Anuario Internacional de Teléfonos, 1973; LACA, 30 de septiembre de 1958, 25 de febrero, 21 de octubre y 4 de noviembre de 1959 y 28 de septiembre de 1960 . En la revisión de tarifas de 1959, las primeras 200 llamadas estaba cubiertas por la cuota: $B O E$, 31 de julio de 1959 , p. 10374.

${ }^{11}$ LACA, 25 de septiembre de 1957. Puede existir distorsión por tratarse del periodo vacacional. 
gaba el trabajo de las operadoras, dificultaba la sincronización y, en definitiva, amenazaba la calidad de los servicios y el rendimiento de los circuitos. Como veremos, paliar estas deficiencias exigirá arbitrar una serie de medidas concretas ${ }^{12}$.

Es cierto que la situación no fue estática sino que algunas características variaron, como sucedió con la tasa de utilización del teléfono: a finales de 1961, los abonados con contador que rebasaban los cien pasos rozaban la mitad, proporción que superaba tres años después el conjunto de abonados del país ${ }^{13}$. No obstante, a lo largo del periodo estudiado persistieron déficits notables, por otra parte no exclusivos de España. Además de las listas de espera, fiel reflejo de ese problema era la pobre teledensidad, que situaba a España a gran distancia de la avanzadilla europea (Suecia) o de economías centrales y tan sólo junto a las periféricas de Europa y Latinoamérica (cuadro 1) ${ }^{14}$. La propia CTNE dibujaba un panorama oscuro sin paliativos - «el ritmo de nuestro desarrollo no corresponde a las necesidades de la demanda»-, remachando tal afirmación con la que tachaba de lujo el teléfono individual con la tarifa vigente ${ }^{15}$.

Profundizar en el conocimiento de la demanda del teléfono en España requiere desagregarla en sus diversas magnitudes. Distinguimos, así, entre demanda bruta anual (peticiones registradas), demanda neta anual (peticiones registradas - peticiones anuladas) y demanda total acumulada (líneas instaladas + peticiones pendientes). Conviene insistir en que la cifra total de teléfonos instalados no reflejaba la demanda con exactitud. La razón es que existía una no desdeñable cifra de peticiones pendientes, es decir, una demanda no satisfecha expresada en las listas de espera. Aquí estribaba el talón de

\section{CUADRO 1}

TELEDENSIDAD EN ESPAÑA. PERSPECTIVA COMPARADA, 1945-1965. TELÉFONOS POR $100 \mathrm{H}$.

\begin{tabular}{|l|c|c|c|c|c|c|c|c|}
\hline Años & USA & Suecia & $\begin{array}{c}\text { Gran } \\
\text { Bretaña }\end{array}$ & Francia & Italia & España & Chile & Portugal \\
\hline 1950 & 28,1 & 23,9 & 10,7 & 5,6 & 2,7 & 2,4 & 2,3 & 1,8 \\
\hline 1955 & 32,2 & 28,9 & 13,46 & 6,3 & 4,2 & 3,4 & 2,2 & 2,6 \\
\hline 1960 & 39,5 & 35,3 & 15,69 & 9,0 & 7,1 & 5,3 & 2,63 & 4,0 \\
\hline 1965 & 45,8 & 44,0 & 19,45 & 13,9 & 10,5 & 8,0 & 2,93 & 5,7 \\
\hline
\end{tabular}

Fuente: Elaboración a partir de CTNE, Memoria(s). La cifra de Chile para 1965 es una estimación.

12 LACA, 21 de febrero de 1956, 30 de septiembre de 1958 y 19 de junio de 1963. Tráfico de tránsito: 16.000 conferencias diarias.

13 LACA, 22 de febrero y 22 de noviembre de 1961, 17 de julio de 1962.

14 LACA, 26 de abril de 1961. En Méjico la teledensidad casi se estancó entre 1955-1965, mientras en Brasil creció muy levemente (de 1,3 a 1,6): CTNE, Memoria(s).

15 LACA, 25 de febrero y 11 de marzo de 1959. 


\section{GRÁFICO 2}

COMPOSICIÓN DE LA DEMANDA DEL TELÉFONO EN ESPAÑA, 1945-1965

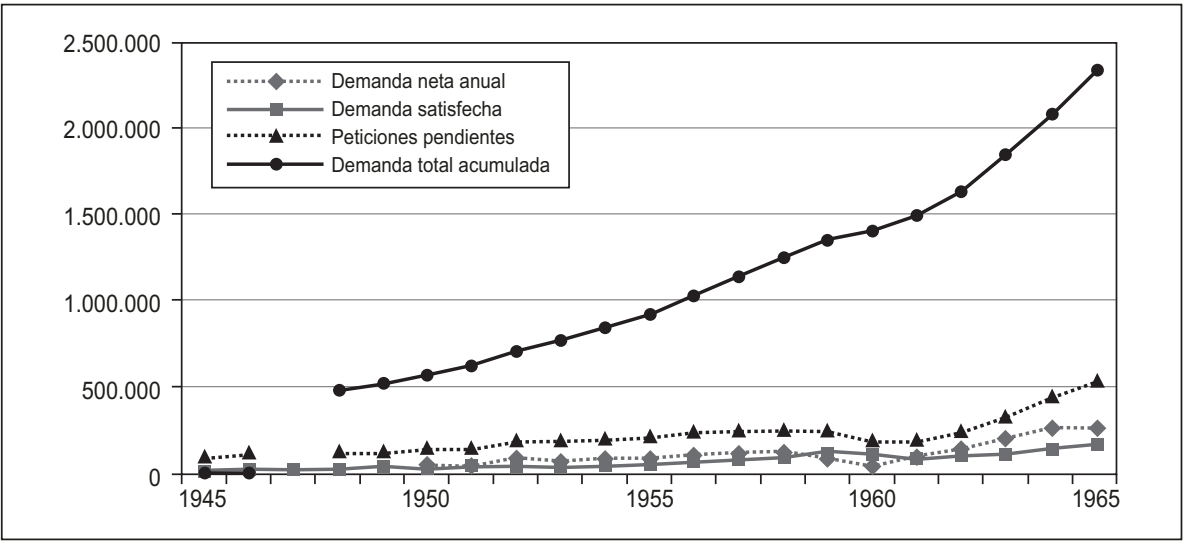

Fuente: Elaborado a partir de CTNE, LACA y Memorias.

Aquiles del problema telefónico ya que quedaba sin cubrir un servicio útil para el ejercicio eficaz de diversas actividades de los peticionarios ${ }^{16}$. Dos circunstancias agravaban una situación ya de por si crítica. Por un lado, existía una demanda oculta - estimada en el doble de la demanda bruta- explicable por el retraimiento de no pocos a solicitar el alta ante las dificultades para conseguir línea; por otro, el periodo medio de espera era muy alto ${ }^{17}$. A tenor del gráfico 2, observamos que las peticiones pendientes se septuplicaron entre 1945-1965, una tasa prácticamente idéntica a la del incremento de la demanda total, mientras que la relación entre peticiones pendientes y demanda total se redujo entre 1950-1961 para aumentar a continuación.

¿Qué evolución siguió la demanda? Para recalcar lo apuntado con nuevos datos y restar el efecto del aumento demográfico, entre 1945-1965 la demanda telefónica por 100 habitantes se multiplicó por 5,06. En momentos puntuales incluso, el número anual de peticiones casi llegó a duplicarse, como ocurrió en 1960-1961. Factor clave de ese incremento fue el empuje de las solicitudes procedentes de particulares. En 1945 había 79.241 estaciones principales particulares frente a 203.919 no particulares, cifras que veintiún años después se habían multiplicado por 11,5 y 4,3 respectivamente. Coeficientes tan dispares habían dado un vuelco importante a la estructura de los abonados, llegando casi a equiparar los dos grandes grupos.

16 LACA, 20 de junio de 1962.

17 LACA, 26 de noviembre, 17 de diciembre de 1958 y 21 de junio de 1955. La inversión necesaria para eliminar la lista de espera se cifraba en 45.000 millones de pesetas en unos siete años, seis veces el capital total de CTNE: 17 de junio de 1959. También puede hablarse de demanda superflua, que se anula en el momento de la concesión de la línea: Presidencia del Gobierno (1967, p. 73). 
Para CTNE estaba clara la vinculación entre demanda insatisfecha y disponibilidad de recursos, por lo que preveía una solución lenta. Una mirada al exterior le mostraba un mal muy extendido al que no escapaban países tan avanzados como Suecia, Suiza y Bélgica, si bien con cifras muy por debajo de las españolas. Contagiada quizás por el optimismo de algunas naciones - Inglaterra se marcaba un horizonte de tres años para eliminar las listas de espera- y con una visión poco ajustada a los hechos — no sólo no se habían reducido sino que se habían multiplicado por 1,37 en cinco años-, España albergaba la esperanza de solucionar el desajuste. La realidad se revelaría mucho más dura, pues tanto Inglaterra como España vieron agravarse la situación ${ }^{18}$.

El notable tirón de la demanda imprimió un fuerte impulso a la oferta, visible en una cuantiosa inversión en infraestructuras de transmisión, centrales y aparatos. El esfuerzo inversor (gráfico 3) sufrió altibajos en los primeros años antes de acelerarse en 1955 y en 1960, con tasas de incremento de 2,21 y 9,88 respecto a 1945 . Aun así, las aspiraciones del público se vieron plenamente colmadas, como muestra que en 1965 persistiese un déficit de oferta similar al de 1945. Sí mejoró la calidad del servicio, ya que el periodo de espera o tiempo transcurrido entre la petición de línea y su instalación se redujo en un 60 por cien en 1945-1965, con lo que no pocos solicitantes vieron cumplidas sus expectativas de forma más rápida ${ }^{19}$.

Del gráfico 3 se desprende igualmente la diversidad de procedencia de los copiosos capitales comprometidos. En buena lógica, los ingresos, que condicionaban las reservas, dependían de la retribución de los servicios amén de una rigurosa gestión. En su nueva etapa posterior a la nacionalización, CTNE heredó una situación en que el auténtico negocio estaba diseñado para obtener fuertes beneficios en el momento del rescate de la operadora por el Estado, que debería abonar a los titulares la cantidad neta invertida, es decir, la inversión total menos amortizaciones e impuestos. De hecho, a lo largo del periodo, el rendimiento neto fue muy bajo y, en términos comparativos, inferior a la pauta europea. A ello se añadió el escaso dinamismo, como prueba el hecho que la ratio de rentabilidad financiera tan solo se multiplicase por un factor de 1,38 en $1945-1965^{20}$, poniendo así en peligro el propio recurso al mercado de capitales. Por su parte, la autofinanciación y el recurso al crédito con excesiva frecuencia amenazaban la confianza de los aho-

18 AET (1977, pp. 20-21); Deloraine (1969, p. 13). CTNE señalaba reducciones del 50 por cien en las listas de espera: 30 de octubre y 18 de diciembre de 1963.

19 Además del intervalo medio de espera para conseguir una línea telefónica, indicadores complementarios de la calidad son el porcentaje de compromisos de instalación cubiertos, las averías y el intervalo transcurrido entre aviso de avería y reparación: Uri (2004, pp. 54-55).

${ }^{20}$ Anuario Telefónico Internacional (1975, p. 173). Tomamos la rentabilidad financiera como la ratio beneficio neto/capital propio: AET (1975, pp. 97-98). En 1958, el producto medio unitario por cuota urbana representaba el 6,01 por cien del coste medio por abonado y se situaba ligeramente por encima del coste medio unitario de conservación y operación. 


\section{GRÁFICO 3}

INVERSIÓN Y FINANCIACIÓN DE CTNE, 1940-1966

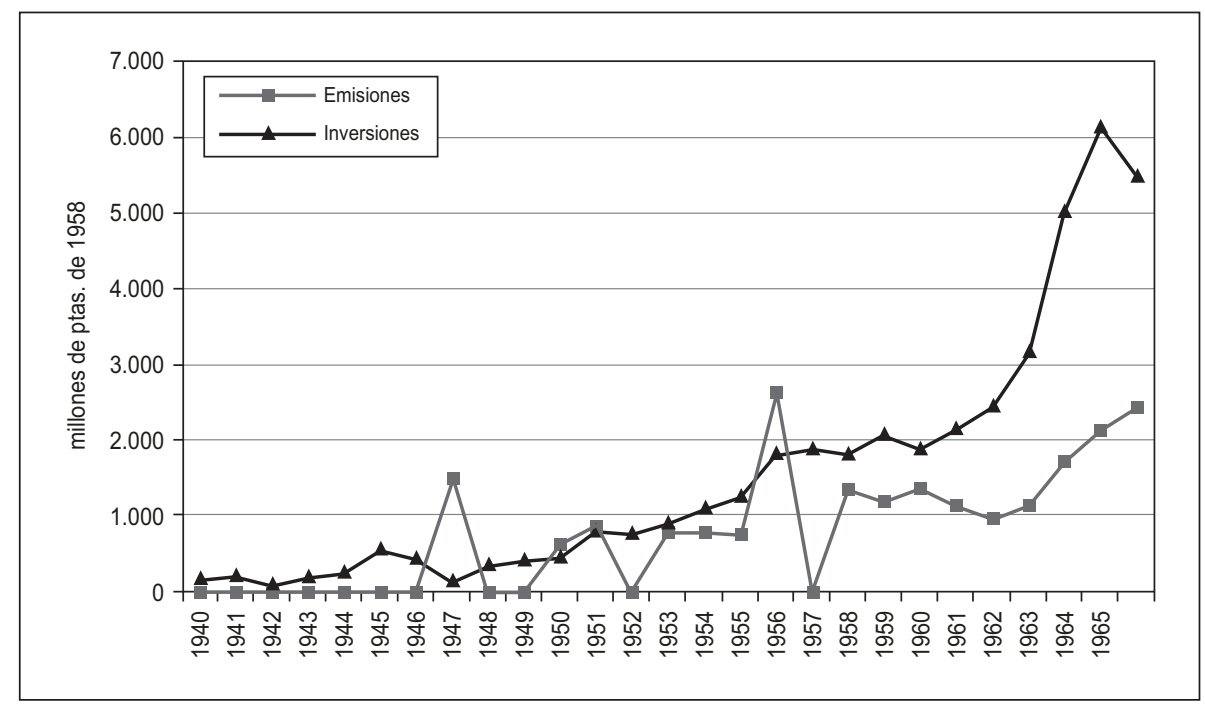

Fuente: Elaboración a partir de CTNE, Memoria(s).

rradores en los valores telefónicos. De esta manera, CTNE se vio obligada a combinar autofinanciación con emisiones de capitales y créditos bancarios. Con ello se volvía al marco regulador - las emisiones debían contar con la autorización del Gobierno, que no siempre actuaba con la celeridad deseada-al tiempo que se entraba de lleno en el marco de la política económica. El resultado de este complejo entramado de factores fue el mantenimiento de una cierta estabilidad en la cotización de las acciones, con alzas entre 1954-1960, acompañada por repartos de dividendos sin sobresaltos y en torno al 7,50 por cien entre 1950-1965.

Conviene preguntarse en este punto si los mercados obraron de forma autónoma o se vieron condicionados. La realidad es que el mercado actuó en respuesta a un marco regulador externo. Si relacionamos la evolución del teléfono con la renta, práctica de probada raigambre en la teoría económica ${ }^{21}$, observamos que, salvo en el cuatrienio 1950-1953, que exhibe un crecimiento de los teléfonos o bien por debajo o bien al mismo nivel que el de la renta, en el periodo restante hasta 1965 el número absoluto de teléfonos se incrementó muy por encima de la renta. Se impone con todo una matización: si descon-

${ }^{21}$ Resulta significativo que, en sus cálculos del desarrollo de las líneas, los ingenieros de las operadoras incluían un amplio abanico de factores económicos, sociales y psicológicos: Bogaerts (1963, pp. 184-195). Estudios clásicos sobre la difusión del teléfono añaden la calidad del management de las empresas: Fischer (1992). 
tamos el crecimiento de la población y hablamos de teledensidad, observamos que la diferencia entre el crecimiento de la teledensidad y el de la renta no es tan pronunciada. Parece, por tanto, fundado afirmar que factores ajenos a la renta tuvieron un papel decisivo en la expansión de la demanda total.

Mecanismo primordial de intervencionismo institucional, el sistema de tarifas estaba a la vez condicionado por el contrato CTNE-Estado y regulado por éste último, que impuso restricciones severas a la elevación de las mismas. Queda así planteado en toda su dimensión el problema del sector en la España de la autarquía y la estabilización.

\section{LA REGULACIÓN ECONÓMICA: LA TENAZA DE LOS PRECIOS POLÍTICOS}

Como es sabido, el Gobierno decidió ejecutar la prerrogativa que se reservó al conceder el teléfono en 1924 y nacionalizó CTNE tras adquirir las acciones en poder de la multinacional ITT ${ }^{22}$. La iniciativa abría una nueva etapa para la telefonía en España, si bien con evidentes elementos de continuidad respecto a la anterior. El monopolio regulado se mantenía pero la participación pública en el capital otorgaba al Estado una capacidad de intervención mucho mayor, al sumar su representación como capitalista y como regulador. Por otra parte, España tomaba una senda diferente a la de numerosos países europeos, en los que se impuso el modelo PTT, monopolio de carácter íntegramente público, inspirado por el objetivo de lograr economías de escala y legitimado por la aspiración al servicio universal ${ }^{23}$. En ausencia de organismo sectorial regulador, sí existente por cierto en el transporte o la siderurgia, fue el nuevo contrato bilateral entre el Estado y la CTNE lo que actuó de instrumento de regulación ${ }^{24}$. Según las nuevas bases

22 Álvaro (2007, pp. 65-96), Calvo (2006, pp. 67-96, y 2008, pp. 455-473). Nacionalización del capital en otros sectores: Gómez Mendoza (1994); raigambre del intervencionismo estatal en el regeneracionismo económico de inicios del siglo xx: Fraile (1998, p. 121); diferencias netas entre nacionalización y valores y objetivos colectivistas: Majone (ed.) (1996, p. 11). Control de precios y racionamiento de artículos de primera necesidad como ejes del intervencionismo estatal en la economía: Barrera y San Román (2000, p. 39).

${ }^{23}$ Millward (2005, pp. 244-266) y Hulsik (2002, p. 77). Telefónica insistió en este aspecto de no estatalismo: Calvo (2006, pp. 67-96). Capitalistas privados llegaron a controlar grandes paquetes de acciones, como fue el caso de P. Díez Fernández, vicepresidente del Banco Nacional de Méjico, propietario de la mayor cervecera del país y accionista particular mayoritario de CTNE con 20.000 acciones (0,096 por cien) en 1960. La gran banca española tenía una participación de 22.800 millones de pesetas (18,49 por cien del total): Velarde (1975, pp. 911-930). En 1962 la inversión privada neta extranjera en el sector ascendió a 19 millones de pesetas (1,55 por cien de la inversión extranjera total en el año): Banco de España (1962, p. 43). En 1965, estaban en manos de inversores foráneos, mayoritariamente suizos, 28.244 títulos de CTNE (Alemania -Adiropa-, 650; Francia, 2.594; Suiza, 25.000): Boletín de la Bolsa de Barcelona, 17 (1966, p. 43).

${ }^{24}$ El enfrentamiento de CTNE con el Gobierno por el contrato, auspiciado por la Banca y materializado en la dimisión del presidente y del consejo, atañía al propio instrumento regulador: 
acordadas en 1946, las tarifas debían ser «equitativas» para el público sin obstaculizar el desarrollo telefónico. La modificación de las mismas, siempre con carácter provisional, se supeditaba a una serie de causas, entre ellas la alteración de los costes, precios de materias primas y equipo, un esquema cercano al llamado cost plus, que permitía hacer frente al incremento de costes sin renunciar a la retribución del capital, pero maniataba a la empresa en la toma de decisiones a medio plazo. Finalmente, el contrato dejaba a la operadora un margen para establecer la estructura de los precios al tolerar cuotas adicionales o especiales, así como tasas de diverso tipo ${ }^{25}$.

El amplio abanico de motivos para justificar una revisión de las tarifas dio lugar a varias solicitudes en el periodo analizado. La primera ocurrió al poco de firmarse el contrato entre el Estado y CTNE y tuvo como desencadenante el previsible aumento de gastos que acarrearía la nueva reglamentación del trabajo ${ }^{26}$. La operadora perseguía «obtener el adecuado rendimiento con el menor trastorno posible para los intereses afectados». El objetivo casaba con la necesidad de mantener los valores telefónicos, financiar la expansión y remunerar al capital, en un contexto de crónica falta de divisas. Contra esta postura realista se alineó el Gobierno a través de su representación, que, aun viendo razonable el aumento, aconsejaba esperar, con la consiguiente agudización de las dificultades ${ }^{27}$. El holgado cálculo de las necesidades permitió a CTNE liberar la no despreciable cifra de 36 millones de pesetas, hasta proceder a un reajuste general. Fruto de un horizonte menos cargado de nubarrones, debido al éxito del reajuste financiero de la compañía, el presupuesto de 1948 superó en cuantía a los anteriores y nutrió una importante expansión ${ }^{28}$.

Más que los motivos en si —renovación técnica y política laboral— la siguiente solicitud de revisión de tarifas trajo como novedad el enfrentamiento entre dos formas de encarar la solución al incremento de los costes — divididas por el acatamiento literal del contrato o una interpretación laxa del mismo-, que se saldó con el triunfo de la continuista. Muy posiblemente,

Calvo (2008, pp. 455-473). Un análisis del papel del Estado como garante de la exclusión de competidores en Gil (2002, pp. 52-53); contraste notable con la no nacionalización en el sector eléctrico - tercera vía- y la autorregulación empresarial a través de UNESA: Garrués y López (2008, p. 2).

${ }^{25}$ Tasas por instalaciones, conexiones, cambios de domicilio o titular y traslado dentro del mismo local: CTNE (1946, pp. 31-32); BOE, 10 de noviembre de 1946. Teóricos del régimen abogaban por subordinar la economía a la política, por vertebrar los elementos económicos y por una estructura lo menos lesiva para el devenir económico del país: Areilza (1940, p. 480).

${ }^{26}$ CTNE habla de «situación seria, crítica de la empresa y que puede llegar a grave»: $L A C A, 26$ de diciembre de 1946. Revisión de tarifas también en RENFE: BOE, 8 de junio de 1946, 159, pp. 4715-4716. Un precedente de la elevación de tarifas bajo la autarquía lo ofrece la Red Telefónica Urbana de San Sebastián en 1942: BOE, 13 de abril de 1948, 104, p. 1375.

${ }^{27}$ Los representantes gubernamentales en el consejo de administración se abstuvieron en la votación que aprobó la revisión de tarifas propuesta: LACA, 28 de marzo y 24 de abril de 1947.

${ }^{28}$ La reglamentación laboral recién aprobada incrementó los gastos en 50.030 .600 pesetas, cantidad inferior a los 86 millones de pesetas previstos: LACA, 25 de junio, 28 de mayo, 11 de julio y 27 de noviembre de 1947 y 15 de junio de 1948. 
hizo perder a CTNE unos años preciosos, al tiempo que reveló de nuevo las trabas en las vías de financiación con que topaba CTNE por su inclinación a no recurrir frecuentemente al crédito. Esta vez se aplicó una clara política discriminatoria, ya que la subida de precios afectaba en especial al servicio interurbano, partida que aportaba casi la mitad de los productos de explotación. Finalmente, la medida adoptada dejaba al descubierto los límites de los planes a muy corto plazo, a la vez que hacía palpable la necesidad de una planificación de mayor alcance y amplitud ${ }^{29}$.

En el proceso de revisión de las tarifas, no sólo cobraban importancia el hecho en sí y la cuantía de la subida sino también los plazos. Los retrasos en la aprobación de los nuevos precios aumentaron notablemente los gastos acumulados, con el consiguiente riesgo para la rentabilidad de la inversión. Además, el reajuste solicitado se quedó corto para afrontar nuevos compromisos laborales y obligó a incluir un alza salarial del 20 por cien por encima de la prevista inicialmente ${ }^{30}$. Las nuevas tarifas de 1953, que recogían las propuestas por la compañía, elevaron los ingresos totales, si bien a costa de recortar el tráfico interurbano, el más afectado por el alza de precios. De esta manera, el aumento de ingresos totales permitió afrontar el incremento salarial pero no resolver el aumento general de costes y la necesidad de retribuir el capital ${ }^{31}$.

Las tarifas actuaron como un instrumento de regularización de la demanda: en 1953, la demanda neta anual cayó un 25,6 por cien respecto al año anterior, cuyo nivel se tardó cuatro años en rebasar. Los agravios comparativos en los que la empresa se amparaba — tarifas telefónicas inferiores a las de otros países y a las de los servicios públicos, así como al índice de precios en España; fuertes aumentos de los materiales, con subidas espectaculares de algunos como el cobre- avivaban una nueva revisión. Ante la necesidad de financiar un plan de obras con una cuantía equivalente a la cuarta parte de la inversión total realizada hasta el momento, la operadora se inclinó primero por la autofinanciación, haciendo recaer sobre los usua-

${ }^{29}$ LACA, 14 de septiembre de 1951 y 21 de febrero de 1952. Fue derrotada una propuesta más audaz de R. Benjumea, regeneracionista, exministro con Primo de Rivera e impulsor de obras hidráulicas y eléctricas. CTNE, que comenzó a entrever una posible confrontación con el personal, no cejó en elogiar su actitud disciplinada frente a una «limitada, reciente, y tendenciosa propaganda». Además, trató de paliar los bajos salarios con mejoras en las condiciones de trabajo (limpieza, iluminación, calefacción), facilidad de acceso a alimentos básicos y medidas de carácter gracioso como las pagas extraordinarias. Testimonios orales en Borderías (1993). Carballo (1975, pp. 452-453), que obvia el diseño de las estrategias de CTNE, achaca los aumentos de tarifas fundamentalmente no a los salarios sino a la «traslación de los precios de monopolio de los bienes de equipo comprados a las filiales de ITT en España».

30 LACA, 26 de octubre, 16 de noviembre y 20 de diciembre de 1951; 3 de mayo, 13 de junio y 15 de julio de 1952; 22 de septiembre y 27 de octubre de 1953 y 23 de marzo de 1954.

31 LACA, 23 de marzo de 1954. Un incremento suplementario de ingresos se buscaba vía unificación de tarifas, tomando como base la distancia de la comunicación y no la diferenciación entre servicio manual o automático. RENFE reajustó las tarifas por idénticos motivos: $B O E, 22$ de febrero de 1954, 53, p. 989. 
rios el esfuerzo de la expansión. Sin embargo, no tardó en decantarse por un régimen mixto mercado de capitales-autofinanciación, opción que contó con el apoyo del delegado gubernamental en la compañía ${ }^{32}$. Al apoyarse parcialmente en el mercado de capitales, CTNE no hacía sino seguir una tradición que había permitido septuplicar el capital social desde 1945, a la vez que buscaba evitar a toda costa la caída de confianza del mercado en los valores de la compañía.

Estaba claro que la falta de recursos ponía en riesgo el plan de expansión del sector. Pero había algo más en juego, que, si estaba en la mente de muchos, no se había manifestado antes con tanta nitidez. En evidente conexión con directrices políticas, la inversión pasaba a considerarse no sólo un medio de evitar el encarecimiento y la paralización de la expansión del teléfono sino una pieza clave del crecimiento económico e industrial. El teléfono había dejado de ser visto como un lujo para convertirse en elemento vital de la economía del país y de las familias. Por ello, las tarifas debían asumir como doble función, evitar penalizar la economía de las clases modestas para no interferir el desarrollo económico y mantener la retribución del capital, en aras de la mejora del servicio y del logro de reservas para invertir ${ }^{33}$.

Las nuevas tarifas fueron aprobadas y se aceptaron como satisfactorias pero no definitivas. Para evitar la posible respuesta negativa de los abonados, se acentuó el recurso a los subsidios cruzados, pieza clave en la actuación «dirigida» de los monopolios y mantenida hasta la introducción de competencia real en los mercados. Se trataba de una discriminación en el tipo de servicio, de forma que la subida sólo afectó a las tarifas interurbanas, mientras las urbanas se mantuvieron, si bien se estableció un recargo por paso de contador y se aplicaron bonificaciones a las llamadas nocturnas y dominicales $^{34}$. En un movimiento ascendente de la demanda insatisfecha y todavía bajo la carestía de materiales y mano de obra, la medida pronto resultó insuficiente. Con ello quedaba claro que, en lo sucesivo, los pequeños reajustes anuales deberían dar paso a una solución a largo plazo, capaz de hacer viable la crecida inversión reclamada por el ritmo de la demanda ${ }^{35}$.

Como puede deducirse de lo apuntado hasta aquí, una de las consecuencias del marco regulador impuesto por el contrato con el Estado fue la vigencia de los precios políticos.

32 LACA, 21 de febrero y 23 de marzo de 1956. La escasez de cobre empujó a adoptar innovaciones ahorradoras de dicho material, entre ellas sistemas multifrecuencia de doce canales de voz: Calvo (2009, pp. 43-72). Sobre el mercado del cobre, la obra de referencia es Pascual y Nadal (2008).

33 LACA, 23 de marzo y 20 de junio de 1956. Los desajustes financieros se estaban solucionando con anticipos bancarios cancelables al final de cada ejercicio: 26 de septiembre de 1956.

${ }^{34}$ LACA, 22 de mayo de 1957. RENFE reajustó las tarifas en 1958: BOE, 5 de agosto de 1958, 186, p. 1361. Inexplicablemente, Carballo (1975, p. 453) desdeña estudiar la repercusión de las alzas de precios sobre la demanda, variable sí contemplada en los cálculos de la empresa: ITT Laboratories of Spain (1973, p. 51).

${ }^{35}$ Fue el ya citado R. Benjumea quien lo subrayó. La inversión se cifraba en unos 8.000-10.000 millones de pesetas: $L A C A, 30$ de septiembre de 1958. 
En la nueva etapa, incluso para los guardianes de la ortodoxia del régimen, había llegado la hora de suprimir los precios políticos en aras del buen funcionamiento del sistema, la debida remuneración del capital y un margen para la autofinanciación. Es decir, ni más ni menos que la alineación con la política propugnada por el sector, eso sí, subordinando las medidas adoptadas a la ordenación del servicio por la vía de su diversificación para ajustarlo a las necesidades y capacidad de consumo de los usuarios ${ }^{36}$.

No bastaba con actuar en determinados segmentos de demanda con una serie de medidas paliativas, a las que haremos alusión más adelante. Engrosar la recaudación se había convertido en urgencia, debido a la confluencia de las necesidades de la expansión de la empresa y de situaciones imprevistas, en medio del ineludible agotamiento de los ingresos derivados del contrato con la aviación militar estadounidense ${ }^{37}$. Sin abandonar el mercado de capitales, se pensó en una cuota de instalación elevada, que reduciría la demanda de líneas individuales, considerada todavía un auténtico lujo. Casi inmediatamente, se propuso aplicar un recargo de dos o cuatro pesetas a las comunicaciones interurbanas, según tuvieran un coste inferior o superior a seis pesetas. La decisión gubernamental de un alza del 50 por cien en las tarifas telegráficas, ya de por si más caras que las telefónicas, parecía avalar la medida. Para aquilatar la vía de la autofinanciación, parecía además oportuno limitar la cantidad destinada a reparto de beneficios que procedía del aumento de tarifas y, para impedir reacciones adversas, aplicar escalonadamente los nuevos sistemas de tarifas ${ }^{38}$.

Con el paso del tiempo, la vinculación entre las estrategias del sector y la política económica fue estrechándose. Así, a nadie parecía molestar que algunos pusieran en manos del Gobierno la capacidad de optar entre una financiación vía aportaciones procedentes del ahorro o a cargo del abonado a través de las tarifas, sin duda porque, en definitiva, era el Gobierno quien debía aprobar las emisiones de valores. En el mismo sentido, había quienes insistían en vincular el problema telefónico y el problema general común a todos los servicios públicos. Para ellos el origen había que buscarlo en una crisis de crecimiento, que exigía medidas adaptadas a las circunstancias económicas de carácter general. Así, el Gobierno decidió ligar la solución del problema de la financiación a una de las fases de la estabilización y, a mediados de 1959, fijó un nuevo régimen de servicios y tarifas ${ }^{39}$.

36 LACA, 21 de enero de 1959.

37 La amortización de obligaciones emitidas en 1929 absorbió 200 millones de pesetas y había disminuido la prima fijada en las ampliaciones sobre la disponibilidad de fondos no retribuidos.

3820 de mayo y 15 de julio de 1959. CTNE consideraba inadecuadas las tarifas del servicio compartido, modalidad que enseguida mencionaremos, a la vez que remachaba las pérdidas ocasionadas por la introducción del servicio medido, cuyos precios no cubrían el coste de lo invertido en la instalación de los contadores: 21 de enero de 1959.

3915 de julio y 29 de julio de 1959. 
Las reacciones de los usuarios a la cuota de instalación no se hicieron esperar. En diversos lugares, renunciaron el 15,3 por cien y el 22,15 por cien de los solicitantes avisados para contratar en los centros automáticos y manuales respectivamente. Por su parte, las solicitudes del servicio urbano sufrieron igualmente un recorte del 23,5 por cien en los cinco últimos meses de 1959 en relación a igual periodo del año anterior, al tiempo que aumentaron en un 15 por cien en un año las bajas de supletorios y extensiones. Las peticiones registradas en 1960 se desplomaron al 51,58 por cien del nivel anterior ${ }^{40}$. Hubo asimismo recortes en el producto medio por línea de abonado (4,3 por cien), especialmente graves en el segmento de mayor consumo $(22,5 \text { por cien })^{41}$. En definitiva, arbitrar soluciones resultaba cuando menos complejo.

\section{RESPUESTAS A LA ESCASEZ: MANAGEMENT, REASIGNACIÓN DE RECURSOS Y RACIONALIZACIÓN}

Contrarrestar las consecuencias negativas de un marco regulador rígido, de un mercado de capital estrecho y de una población con reducido poder adquisitivo requirió adoptar una diversidad de cambios en la gestión del servicio. Había que enfrentarse asimismo a la finalización del contrato de suministro con Standard Eléctrica y de su primera prórroga, contrato doblado por otro de asesoramiento técnico con ITT, ambos firmados en 1945. Las medidas aplicadas coincidieron con la paulatina pérdida de peso de los consejeros de la multinacional en la dirección de la empresa y el aumento del peso de la delegación gubernamental ${ }^{42}$.

Una respuesta al desfase existente entre la demanda y los recursos disponibles para satisfacerla fue la innovación tecnológica en forma de servicio urbano medido por contador. Mencionado en párrafos anteriores, proporcionaba información precisa sobre el total de llamadas, la facturación para la empresa, las sobretasas y el impuesto, por no hablar del estado del empleo, los servicios de explotación y la evolución de la productividad. En 1959, el servicio medido se había aplicado ya a nueve centros con algo más de medio millón de líneas, cifras que en un solo año se vieron engrosadas hasta totalizar sesenta poblaciones y el 81,6 por cien de los teléfonos automáticos. Continuando la progresión, en abril de 1961, el número de poblaciones afec-

4017 de febrero de 1960; AET (1977, p. 29).

4123 de septiembre de 1959. Hubo comportamientos muy diferenciados, visibles en la desagregación: disminución del tráfico en 1960 en relación a 1959 (11 por cien en Madrid, 3 por cien en Valencia, 2 por cien en Barcelona); aumentos de 1 por cien en Bilbao y Sevilla. Mejoró la calidad del servicio por reducción de demoras (de hasta el 55 por cien en 1959 al 38 por cien en 1961) y de las celebradas dentro de los treinta minutos siguientes a su petición (85-90 por cien del total): 16 de diciembre de 1959, 17 de febrero de 1960 y 31 de mayo de 1961.

42 LACA, passim; ACASTE; Álvaro (2007, pp. 65-96). 
tadas se había incrementado en veinticuatro y el de los teléfonos automáticos en un 7 por cien, mientras que, al cabo de un año, el nuevo sistema de tarificación se aplicaba al 95,2 por cien de las líneas automáticas existentes ${ }^{43}$.

El mejor conocimiento de las peculiaridades del servicio permitió someterlo a principios de racionalización, ajustando los circuitos a las necesidades reales ${ }^{44}$. Por su parte, la implantación del servicio medido no podía por menos que incidir directamente sobre la estructura reguladora a través de la reivindicación de la modificación de tarifas. Si el incremento del tráfico no implicaba siempre un aumento paralelo de ingresos, hecho observado en las zonas de ensayo y que anticipaba lo que sucedería una vez la medición se generalizase, parecía obligado aumentar las tarifas, sin lo cual no había plan de ampliación posible. La duda estaba en el alcance del reajuste, en si debía ser total o parcial ${ }^{45}$.

Conforme a las expectativas, la implantación de los nuevos sistemas de comunicación, conservación y control permitió reducir personal y, por tanto, recortar una partida que representaba los dos tercios de los gastos de explotación. Los 24 empleados por 1.000 teléfonos de 1945 se redujeron en un 29,16 y 58,3 por cien en las dos décadas siguientes ${ }^{46}$. Factor no desdeñable de la mejora fue la inversión en capital humano, gracias sobre todo a la Escuela Técnica de Telefonía, y a la automatización de las llamadas y de los trabajos administrativos. Consecuencias de todo ello fue el aumento de la productividad del trabajo, que casi se duplicó entre 1950-1960 ${ }^{47}$.

Otra de las medidas adoptadas para atenuar el problema consistió en compartir una línea entre dos abonados con la garantía del secreto en la comunicación mediante un sencillo dispositivo en los aparatos que permitía a un usuario de la línea bloquear el acceso al otro durante la llamada. Tratábase de una variante de explotación barata, estrechamente vinculada a las bajas tarifas, capaz de hacer compatible el aumento de las facilidades de acceso al servicio y el del número de abonados. Sin pretensiones de panacea — debía además conjugarse con otras medidas, como la instalación de centralitas de barrio- posibilitaba regularizar la demanda y hacer frente al in-

${ }^{43}$ LACA, 28 de septiembre de 1960; 26 de abril, 31 de mayo, 12 de julio y 22 de noviembre de 1961; 28 de marzo y 26 de septiembre de 1962. Las mejoras hicieron disminuir la duración de las llamadas: 31 de mayo de 1961. El sistema medido afectó en abril al 32,3 por cien de los abonados de Madrid y al 25,8 de los de Barcelona: 18 de junio de 1958.

${ }^{44}$ Así sucedió en el área Málaga-Torremolinos: 16 de julio de 1958. Nótese la importancia del turismo como acicate.

${ }^{45}$ CTNE recalcaba la amenaza que suponía para los ingresos la automatización porque muchos abonados completarían el cupo de llamadas fijado en la cuota mensual con conferencias interurbanas: 21 de enero de 1959. Insistencia en el aumento de tarifas como elemento reconductor de la demanda, con la consiguiente mejora en el uso de los recursos disponibles: 25 de febrero de 1959 .

${ }^{46}$ Servicios de explotación: 14.446 empleados: 15 de junio de 1960.

${ }^{47}$ La productividad, expresada a través del producto de cada empleado por 1.000 unidades, se multiplicó por un factor de 1,87 en la década 1950-1960: LACA, 15 de junio de 1960. Destaca la introducción de la electrónica y de las fichas perforadas, con efectos espectaculares dado el colosal volumen de datos manejados. 
cremento de la lista de espera. Así, cálculos diversos permitían albergar la esperanza de reducir las peticiones pendientes a la quinta parte en tres años ${ }^{48}$.

La extensión del servicio compartido obedeció a la lógica del efecto demostración. El éxito de los ensayos efectuados en Córdoba, ciudad piloto por su tamaño medio, llevaron a repetirlos en una segunda ciudad similar - Castellón- antes de aplicarlo en grandes núcleos - Madrid, Barcelonay a otras poblaciones ${ }^{49}$. En Córdoba a finales de 1959 se utilizaban 1.200 líneas que daban servicio a 2.400 abonados, cifra equivalente a las tres cuartas partes de las peticiones cursadas. La práctica demostró que la distribución de los abonados a ambos servicios —el compartido y el de línea individual - según el número de llamadas no variaba sustancialmente. Sí había una diferencia abismal en términos recaudatorios ${ }^{50}$.

Diferentes sistemas de carácter paliativo se centraban en el mismo segmento de demanda, el de baja capacidad de consumo, sin recursos para pagarse un teléfono individual de uso exclusivo. A él iban destinadas medidas como las centralitas semiautomáticas en barrios importantes y los teléfonos de portería con el enlace directo de los vecinos. Un serio avance hacia la universalización del acceso al teléfono fueron los teléfonos públicos, en cuyos aparatos se introdujeron incluso mejoras - las cabinas de monedas-con la finalidad de evitar perturbaciones y consiguientes quejas de los usuarios ${ }^{51}$. A favor del éxito relativo de estas medidas hablan las cifras. Mientras en 1945 solo había 3.356 teléfonos públicos con una recaudación anual de seis millones de pesetas, una década después la cantidad se había cuadruplicado con creces, con una recaudación anual de 80 millones, y decuplicado generosamente a inicios de 1961, momento en que las centralitas de barriada eran 80 y los abonados $16.000^{52}$.

486 de abril de 1960 y 17 de junio de 1964. La afirmación de la baratura contradice otra en la que CTNE señalaba la exigencia de mayor inversión de capital: 17 de febrero de 1960. Limitado inicialmente a las nuevas instalaciones, iba destinado al sector de la demanda con escaso poder adquisitivo y bajísima tasa de utilización. Ello aconsejaba tocar sólo la cuantía de las llamadas libres y no la de instalación y abono.

4920 de mayo, 21 de octubre y 16 de diciembre de 1959; 6 de abril de 1960. En preparación todas las centrales de Madrid para el servicio compartido: 28 de septiembre de 1960. La implantación del servicio en Córdoba fue publicitada en la prensa y radio locales.

50 Cifras de diciembre 1959-enero 1960: menos de 100 llamadas (Córdoba): 76,7 por cien de los 2.281 abonados adscritos al servicio compartido y 75,9 por cien al servicio por línea individual; entre 100-200 llamadas: 19,3 y 22,2 por cien, respectivamente; más de 200 llamadas: 4 y 1,9 por cien, respectivamente. Gran discrepancia en el producto medio por línea: 0,85 pesetas en el servicio compartido frente a 10,6 pesetas en el individual, uno de cuyos segmentos, el de los abonados por encima de las 200 llamadas, alcanzaba las 43 pesetas de promedio: LACA, 16 de diciembre de 1959; 17 de febrero, 16 de marzo y 20 de julio de 1960.

51 El nuevo sistema reunía las ventajas de la prolongación de la llamada por simple adición de nuevas fichas recuperables en caso de no utilización: 17 de octubre de 1960. En Córdoba, el servicio compartido se complementó con dos nuevas centralitas de barriada con el objetivo de captar nuevos usuarios.

5221 de enero de 1959, 17 de octubre de 1960 y 22 de febrero de 1961. Los teléfonos públicos en centros automáticos alcanzaron un extraordinario desarrollo tanto por número de aparatos en 
Con todo, en conjunto, las medidas resultaron insuficientes e incluso algunas no hacían sino reclamar soluciones que atajaran el problema de raíz. Si en 1958 se hablaba de la escasa rentabilidad del servicio telefónico urbano y del riesgo de pérdidas debido al desfase entre el precio de los materiales y las tarifas, al año siguiente CTNE consideraba llegado el momento de pasar del estudio de la ampliación de los servicios en sus aspectos económico y técnico a su ejecución ${ }^{53}$.

\section{REGULACIÓN Y ESTABILIZACIÓN ECONÓMICA}

En resumidas cuentas, el modelo de servicio público que el franquismo propugnaba era una quimera debido a la dificultad de conjugar baratura, calidad, alta inversión y adecuada remuneración del capital, como se ha visto.

En 1959, en pleno debate sobre la conveniencia de revisar las tarifas, entró en liza otro elemento con fuerte capacidad de incidir sobre las soluciones: el viraje en la política económica hacia una mayor liberalización y apertura. Aun visto con buenos ojos un aumento racional de tarifas interurbanas, debía supeditarse a las medidas de política económica —ordenamiento económico- que preparaba el Gobierno ${ }^{54}$.

Buena medida del impacto de las políticas aplicadas es el comportamiento de las emisiones privadas. En ese año de 1959, las destinadas a teléfonos crecieron por encima de las emisiones privadas totales, razón por la cual su participación porcentual pasó del 20,86 al 29 por cien. Sin embargo, este empuje no se mantuvo y en los dos años siguientes los porcentajes sufrieron una drástica caída de 6,18 y 10,9 puntos, en agudo contraste con la fortaleza de la posición de los servicios en las emisiones privadas totales. En el bienio 1959-1960, la mayoría de las industrias recibieron el impacto del plan de estabilización, que, junto a la liberalización económica, implicó importantes medidas de choque, como afirma García Delgado. Las emisiones se recuperaron a continuación, llegando a triplicarse con creces en 1965 con relación a 1960. Los teléfonos recuperaron posiciones en relación al conjunto de los servicios sin llegar a alcanzar sin embargo las conseguidas en 1958-1959. De acuerdo con los datos del cuadro 2, en 1954-1965, la formación bruta de capital se multiplicó por 28,23 en el conjunto de la economía

servicio como por recaudación media: 28.296 aparatos, de ellos 13.033 en Madrid y Barcelona, con recaudación de 444,13 pesetas por aparato. Los productos de explotación de esta modalidad de servicio se multiplicaron por un factor de 237 entre 1946-1965: CTNE, Memoria(s).

5318 de junio de 1958 y 20 de mayo de 1959.

${ }^{54}$ Véase Tamames (1976, pp. 467 y ss.). Tratamiento diferenciado mereció la nacionalizada RENFE, que en 1959 obtuvo financiación extranjera del norteamericano Development Loan Fund, especializado en operaciones a largo plazo, mediante un préstamo por 14,9 millones de dólares avalado por Hacienda: BOE, 30 de mayo de 1959, p. 7.748. 


\section{CUADRO 2}

FORMACIÓN BRUTA DE CAPITAL EN EL SECTOR TELEFÓNICO (millones de pesetas)

\begin{tabular}{|c|c|c|c|c|c|}
\hline & 1. España & 2. CTNE & CTNE/Spúbl & CTNE/Spriv & $\mathbf{2 / 1}$ \\
\hline \multirow{3}{*}{1954} & $68.291,2$ & 771 & 5,26 & 1,44 & 1,13 \\
\cline { 2 - 6 } & 78.553 & 926 & 5,25 & 1,52 & 1,18 \\
\cline { 2 - 6 } & $96.253,4$ & 1.489 & 6,97 & 1,99 & 1,55 \\
\cline { 2 - 6 } & $118.386,6$ & 1.690 & 6,75 & 1,81 & 1,43 \\
\hline \multirow{3}{*}{1958} & 137.532 & 1.848 & 5,6 & 1,8 & 1,36 \\
\cline { 2 - 6 } & 114.096 & 2.226 & 6,94 & 2,71 & 1,95 \\
\cline { 2 - 6 } & $117.774,2$ & 2.079 & 5,99 & 2,5 & 1,76 \\
\cline { 2 - 6 } & 156.160 & 2.385 & 5,37 & 2,13 & 1,52 \\
\cline { 2 - 6 } & $199.265,6$ & 2.872 & 7,13 & 1,81 & 1,44 \\
\cline { 2 - 6 } & $235.864,2$ & 4.047 & 7,78 & 2,2 & 1,71 \\
\hline \multirow{2}{*}{1965} & $267.721,7$ & 6.860 & 10,84 & 3,35 & 2,56 \\
\hline
\end{tabular}

Fuente: Anuario Estadístico Telefónico (1977: 146). Spúbl: Servicio público; Spriv: Servicio privado.

española mientras en el sector de teléfonos lo hizo por 47,57. Este mejor comportamiento le permitió incrementar su peso en el servicio privado y, sobre todo, en el público.

El mismo argumento de la economía del país - y del sector, por supuesto - abonaba las aspiraciones a un nivel adecuado de inversión para mantener la expansión de las instalaciones. "Adelante la inversión», decía el Gobierno por boca de su representante, pero con las oportunas correcciones impuestas por el nuevo ordenamiento económico nacional. «¿Novedades, cuando las fuentes de inversión previstas en el plan son las de siempre: el ahorro privado, el capital exterior y la autofinanciación?» — replicaba el portavoz de la Banca ${ }^{55}$. Habrían de pasar unos años para que, de nuevo, el Gobierno volviera a destacar su interés en el avance del servicio como instrumento de desarrollo del país, junto a la necesidad de pasar de las formulaciones teóricas a las propuestas prácticas ${ }^{56}$.

Vinculadas sin duda al ya citado plan de estabilización y coindiendo con la afluencia de capital extranjero, en 1959-1961 entraron en vigor una serie de medidas que contribuyeron a acrecentar la solvencia financiera del sec-

55 Como portavoz de la Banca actuó Epifanio Ridruejo, del Banco Español de Crédito: 17 de junio de 1959. El plan para 1959, dotado con 2.494 millones de pesetas, contemplaba el reciclaje de material aprovechable.

5622 de enero de 1964. 
tor y, por ende, su capacidad inversora. Entre ellas, destacan las sobretasas, que pretendían proporcionar a CTNE medios complementarios de financiación para hacer frente de forma rápida a un aumento de la demanda de servicio sin necesidad de recurrir al mercado de capitales. Las sobretasas afectaban al servicio urbano por partida doble - a las cuotas de instalación y al servicio medido por contador-, así como a las conferencias interurbanas, con ánimo de introducir criterios de mercado en los precios sin aludir a la odiosa elevación de tarifas. Al mismo tiempo, se modificaron los impuestos que gravaban algunos servicios ${ }^{57}$.

Una eficaz labor de lobby en las Cortes y en el Gobierno arrancó compensaciones a favor del sector por el incremento de gastos financieros anejo a la ampliación de los servicios. Una ley abrió el camino para reforzar los ingresos de la cuenta de explotación. Por su parte, una tasa única de 1.000 pesetas sustituyó a las dos que discriminaban los teléfonos individuales y compartidos. Para acabar esta breve enumeración, un organismo especializado - la Dirección General de Tributos Especiales_- propuso a Hacienda eximir al sector del impuesto complementario y de los de emisión y negociación. Como en un intento por mostrar que no siempre ahoga quien aprieta, el Estado dio balones de oxígeno al sector mediante la concesión de créditos vía devengos no ejecutados y de un crédito extraordinario de 8.416 .337 pesetas con el objetivo de compensar a la Compañía Telefónica Nacional de España del 50 por cien de los gastos ocasionados por modificación de líneas telefónicas en ejercicios anteriores ${ }^{58}$.

La aplicación de las sobretasas telefónicas tuvo una incidencia indudable. Dada la imposibilidad de discriminar en los contadores las llamadas urbanas e interurbanas, los abonados con una cifra de llamadas muy inferior a las incluidas gratis en la cuota mensual podían completar sin recargo alguno ese cupo de cuota con llamadas interurbanas, más caras según las tarifas vigentes, proceder que hacía disminuir los previsibles ingresos ${ }^{59}$. Sin embargo, lo que ocurrió fue una contracción de ingresos, de forma que, a finales de 1960, disminuyeron los productos en un 0,14 por cien y los gastos en un 1,3 por cien del presupuesto. Quizás por ello, CTNE adoptó una actitud cautelosa al

57 CTNE se beneficiaba de la medida porque, si bien las sobretasas engrosaban directamente las arcas públicas, la recaudación permitía financiar la concesión de créditos a la compañía. Por su parte, el Estado veía aliviado el compromiso de adquirir acciones procedentes de las nuevas emisiones a que como accionista estaba obligado: $B O E$, 31 de julio de 1959, 182, p. 10373, y 89, 13, abril de 1962, p. 4962; LACA, 21 de noviembre y 14 de diciembre de 1960; 21 de noviembre de 1960; BOE, 31 de julio de 1959, 182, pp. 10373-10374; 13 de abril de 1962, 89, p. 4962; 14 de abril de 1962, 90, p. 5040. Ejemplo de la importancia de las sobretasas por llamadas entre 101-200, en Córdoba el 43,9 por cien de la recaudación total correspondió a esa carga: $L A C A, 16$ de diciembre de 1959 y 17 de febrero de 1960.

5818 de enero de 1961; BOE, 31 de diciembre de 1963, 313, pp. 18241-18242. CTNE atribuía el progreso alcanzado a la mejor organización y a las facilidades concedidas por el Gobierno: 28 de marzo de 1962.

5921 de noviembre y 14 de diciembre de 1960. 
decidir instalar nuevos sistemas de alta frecuencia en varias rutas con equipos trasladados de otras zonas.

La estrecha relación entre política sectorial y estabilización económica tuvo como corolario el refuerzo de la presencia de miembros del Gobierno en los órganos rectores de la operadora. Un ejemplo fue el nombramiento de un nuevo consejero de CTNE para subsecretario de Hacienda, lo que elevaba a dos el número de consejeros con el mismo cargo en diferentes ministerios, lógicamente los de mayor vinculación con la compañía por su contrato con el Estado ${ }^{60}$.

Tras la llamada «década bisagra», la política económica del franquismo dio paso sucesivamente a los planes de estabilización y de desarrollo, que impulsarían entre 1963-1975 un intenso crecimiento económico ${ }^{61}$. En las postrimerías de 1962 ya se hacían visibles los nuevos aires, que pretendían reconducir los planes previstos en el sector e incluirlos como proyecto bienal en los objetivos del Comisario del Plan de Desarrollo Económico ${ }^{62}$.

Aun reconociendo al sector la prerrogativa de planificar, el Gobierno no quería que se albergara duda alguna sobre su facultad exclusiva a la hora de fijar los ritmos, el alcance y la forma. Por entonces, algunas empresas públicas atravesaban momentos clave, entre ellas RENFE, que impulsaba un plan general de reconstrucción por siete años con el beneplácito del Banco Mundial ${ }^{63}$.

\section{EPÍLOGO}

La relación oferta-demanda-regulación cambió sustancialmente a partir de 1963, fecha divisoria a partir de la cual el sector, acostumbrado a volar con plomo en las alas, empezaba a desprenderse del lastre y a remontar con fuerza. El teléfono había entrado en una ola expansiva, convertido ya de lujo en «necesidad en todos los órdenes de la vida» ${ }^{64}$. Nuevos y potentes segmentos de demanda vinieron a añadirse a la existente, esta vez impulsados por el auge del turismo — uno de los ejes del desarrollismo—, que obligó a desplegar esfuerzos para instalar infraestructuras adecuadas en las zonas de mayor atracción ${ }^{65}$.

6025 de octubre de 1961.

${ }^{61}$ Tortella (1994) y García Delgado (1987, p. 170). De 1957 es la Oficina de Coordinación y Programación Económica.

6226 de septiembre de 1962.

${ }^{63}$ Trátase del plan Guadalhorce, así llamado por el título que ostentaba R. Benjumea, al frente de RENFE desde 1947.

6424 de octubre de 1962. Otras declaraciones sobre la importancia del teléfono: «no un lujo sino una verdadera necesidad, incluso como instrumento de trabajo, base de la actuación de la compañía en busca del beneficio del país»: 20 de noviembre de 1963.

${ }^{65}$ Frente a la irrupción del turismo - entre 1950-1967 el número de visitantes se multiplicó por 25,5- la política turística, que había llevado en 1962 a la creación de una subsecretaría, tenía como preocupación esencial las infraestructuras. 
Era el inicio de una nueva etapa de expansión con un evidente cambio de ritmo, que se acentuaría a partir de 1965. Pese a los pronósticos —o los argumentos esgrimidos por CTNE en su momento- todavía no se había agotado la importante fuente de ingresos procedentes de la fuerza aérea militar norteamericana que en 1960-1965 habían engrosado las cuentas de CTNE con 347.260.000 pesetas en aportaciones especiales. La expansión se había convertido en un apremio para normalizar la demanda de teléfonos y fomentar el crecimiento de los servicios. De ese substrato surgió un ambicioso "plan de desarrollo" por quince años, cuya primera etapa debería comenzar en 1963 y completarse hasta alcanzar el objetivo de satisfacer la demanda en su totalidad, proviniese de grandes empresas o de los más modestos particulares. Había irrumpido una nueva modalidad de planificación - la indicativa - y la inversión había alcanzado cifras inverosímiles hasta el momento ${ }^{66}$.

El plan, que no parecía topar con obstáculos financieros, pretendía acudir a fuentes de financiación diversificadas. Si hacemos caso de los datos del primer año -1963 - , ponía énfasis en el mercado de capitales pero reservaba una cuarta parte para autofinanciación ${ }^{67}$. Respecto a los efectos de arrastre sobre la industria y el conjunto de la economía, al final del periodo la contribución del teléfono a la economía española representaba el 0,2684 por cien del empleo, el 0,496 del valor añadido y el 2,8 de la formación bruta de capital, cifras que multiplicaban por $1,75,1,39$ y 2,48 , respectivamente, las de 1954 (véase cuadro 2) ${ }^{68}$.

Dentro de un modelo imperante que conjugaba la tecnología del hilo de cobre, los circuitos múltiples y el monopolio ${ }^{69}$, en la nueva etapa la modernización pasaba por intensificar el recurso a la radio, con circuitos de alta frecuencia de múltiples canales transistorizados, y a los cables coaxiales. Un nuevo tipo de central, más versátil, sencilla y eficaz llamaba a las puertas de Gobiernos y empresas de todo el mundo todavía con escaso éxito ${ }^{70}$.

${ }^{66}$ El coste total del plan ascendía a 83.998 millones de pesetas: LACA, 26 de setiembre de 1962 .

${ }^{67}$ De los 3.660 millones de pesetas presupuestadas para 1963, el 33 por cien se asignaba a la última ampliación de capital; 41 por cien a la emisión de obligaciones y 26 por cien a recursos propios: 27 de marzo y 12 de mayo de 1963.

${ }^{68} A E T$ (1977, pp. 143-146). El objetivo era llegar a duplicar casi los 7.669 centros en servicio; automatizar hasta el 90 por cien y alcanzar una densidad de 20 teléfonos/100 h.; 7,5 millones de circuito interurbano y 90 por cien de conferencias interurbanas automáticas.

${ }^{69}$ El modelo predominante evolucionó con el tiempo hacia el llamado modelo abierto global, que conjugaba cambio tecnológico - fibra óptica, microondas y servicios empaquetados- e institucional -la desregulación: López (On-line).

70 LACA, 27 de marzo de 1963. Cables coaxiales y radio relevada, que soportaban hasta 1.200 conversaciones simultáneas, fueron fruto del convenio con la fuerza aérea US: 21 de febrero de 1956. CTNE firmó un acuerdo con Marconi que implicó a la vez a SESA. La radio múltiple relevada y la conmutación interurbana arrancan al inicio de la década de 1950. Pese a realizaciones indiscutibles, el peso de la radio en el total invertido en equipo de centrales se mantuvo entre 1952-1966. Las centrales según el sistema Rotary se reemplazaban por las de barras cruzadas del Pentaconta: Calvo (2009, pp. 43-72). 
Los avances en los nuevos instrumentos de comunicación obligaron a CTNE a sumarse a la carrera internacional de las comunicaciones por satélite. Ante una apuesta estratégica que requería tecnología punta, CTNE resolvió rentabilizar su fácil acceso a la capacidad técnica de ITT, decisión que tuvo consecuencias de largo alcance para su presencia en las comunicaciones por satélite ${ }^{71}$. No menos importante que la ampliación y modernización de las infraestructuras físicas fue el rediseño de la red con objeto de corregir los efectos negativos del trazado radial y permitir la innovación en servicios ${ }^{72}$.

Inherentes a todo servicio público, las tarifas continuaron sobre el tapete, debido fundamentalmente a la gran disparidad que, en términos absolutos y también considerando la renta per capita, guardaban las telefónicas respecto a las de otros servicios y a algunas del extranjero, rasgo este último perfectamente visible en el gráfico 4 . Pese a todos los avances, pues, subsistía un problema de financiación y así lo admitía explícitamente el representante gubernamental en 1964. En algo debieron influir las dificultades productivas de Standard Eléctrica, suministradora principal de la operadora, debidas a la escasez de materias primas pero convendría tomar con cautela

\section{GRÁFICO 4}

TARIFAS Y RENTA NACIONAL PER CAPITA, 1965 (\%)

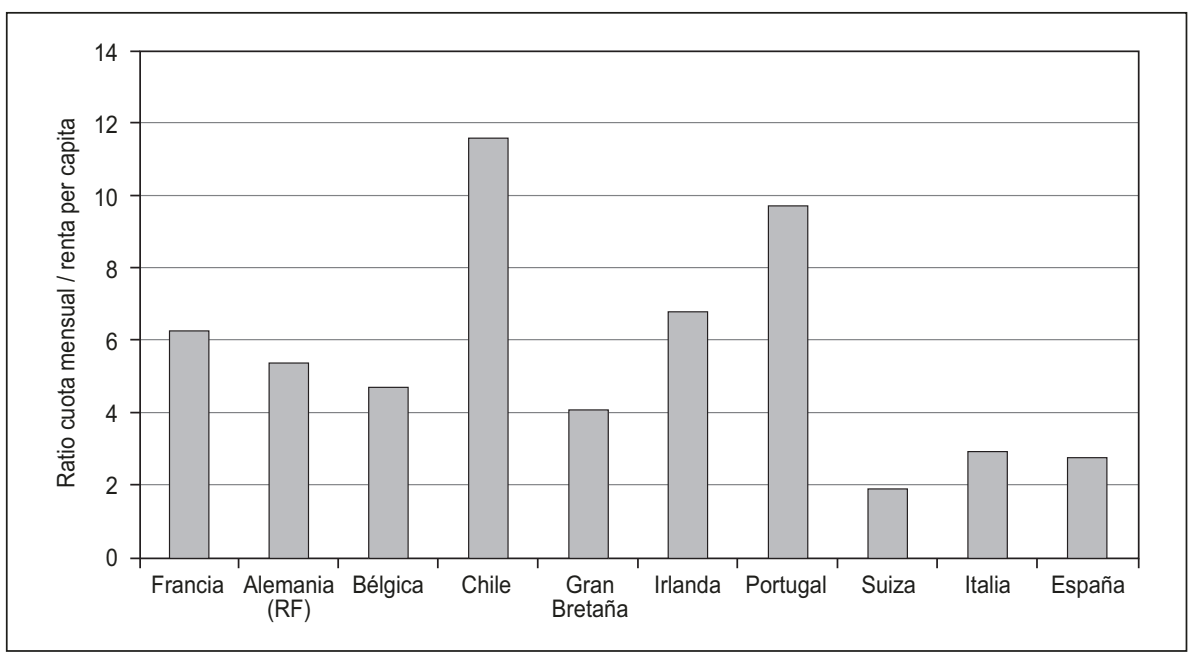

Fuente: Elaboración a partir de World Resources Institute y CTNE.

${ }^{71}$ Fue ITT la que ofreció su capacidad tecnológica: 17 de julio de 1963.

${ }^{72}$ Fernández y Rose (en prensa). Hitos fundamentales fueron la conversión de la provincia en unidad básica y el refuerzo de la red de malla. La integración de la red de Guipúzcoa fue un importante avance: LACA, 23 de febrero de 1950, y Gutiérrez (2008, pp. 75-94). 
las posturas que conceden un excesivo peso a la manufacturera en los retrasos de la operadora ${ }^{73}$.

CTNE reconocía copiosas dificultades halladas en los años inmediatamente posteriores a la nacionalización, tan sólo atenuadas a partir de 1951, sin revelar con todo las causas. Ciertamente no hay una posición oficial unánime y tajante en los órganos directivos de CTNE al respecto aunque sí alusiones a la insuficiencia de capacidad de Standard Eléctrica, S. A. (SESA), junto a una propensión a elogiar los servicios prestados por ésta a la operadora. Además, la inserción de ésta última en el grupo industrial de ITT propiciaba el recurso al mercado internacional, de forma que en ocasiones se importó equipo, como ocurrió bajo el mandato de Suanzes. La evidencia cuantitativa apunta a una diversidad de motivos, ya que entre 1947-1953, la producción de aparatos por SESA creció ligeramente por encima de las ventas, cosa que no sucedió con la producción de líneas ${ }^{74}$. Está casi de más relacionar esta escasez de líneas con la introducción del servicio compartido.

En una interesante reflexión, un consejero de CTNE se mostraba reacio a plegarse únicamente a la presión de la demanda y apuntaba a un posible nexo con la baratura relativa de las tarifas respecto a la evolución del coste de la vida y especialmente a los servicios públicos restantes ${ }^{75}$. Lo cierto es que existía todavía una crecida demanda insatisfecha y no se había abandonado aún las líneas compartidas. La búsqueda en el exterior de fórmulas idóneas permitía constatar insatisfacción de los usuarios en cualquiera de los dos sistemas adoptados —el que privilegiaba la necesidad mediante la concesión de líneas a las solicitudes más urgentes acompañada de la instalación de teléfonos públicos para los abonados con rentas bajas; y el sistema compartido en sus distintas modalidades ${ }^{76}$.

El final del periodo analizado cierra una trayectoria circular, con el planteamiento de la revisión de tarifas como necesidad acuciante para afrontar la nueva alza de costes laborales, así como la ampliación de las instalaciones

${ }^{73}$ Frente a Plaza (1989, pp. 390-408), Carballo (1975, p. 376), culpa de los fallos a las fuentes de financiación dificultosas y a los fallos de SESA. En las comparaciones de tarifas se tiende a simplificar, cuando la actitud debería ser de extremada cautela debido a las diferentes contraprestaciones que pueden entrañar. El incremento de salarios por debajo del nivel de precios logrado por los ampliamente reconocidos sindicatos, dicho sea con todo su énfasis, obligó al Gobierno británico a elevar las tarifas en 1955, si bien se mantuvieron las llamadas gratuitas por abono: HC Debates, 11 de abril de 1956, vol. 551, cc. 215-220.

${ }^{74}$ Calvo (2009).

7518 de marzo de 1964, Calvo (2009).

${ }^{76}$ Las líneas compartidas (party lines) se remontan a la infancia del teléfono y revestían modalidades distintas por países: sin discriminación ni privacidad en Inglaterra y con garantía de privacidad en Estados Unidos. Evolución dispar en ambos países: práctica desaparición de esa modalidad en Estados Unidos y mantenimiento en Inglaterra, país en el que la cifra se mantuvo entorno a un millón en 1959, con el 37 por cien de los abonados residenciales, y 1966, una auténtica desgracia, al decir de un miembro de los Commons, en el país en que la derecha política consideraba el Post Office como niña mimada de los defensores de sistemas colectivistas: HC Debates, 31 de marzo de 1952, vol. 498, cc. 1182-1261 y 24 de noviembre de 1959, vol. 614, C35W. 
y la intensificación de los trabajos de conservación ${ }^{77}$. Ya con el ascenso a la presidencia de Barrera de Irimo, antiguo delegado del Gobierno, se aprobaron los nuevos precios, cuya aplicación se iniciaba a finales de $1965^{78}$. El plan de construcción para el año siguiente tenía un cariz continuista y de transición hacia un futuro programa de desarrollo telefónico, que despejaba el camino hacia una etapa de expansión sin precedentes.

\section{CONCLUSIÓN}

Pasado por el tamiz de la perspectiva histórica y comparada -modelo PTT, predominante si bien no único en Europa, en un marco político-económico netamente discrepante-, el servicio telefónico español reafirma algunas de las hipótesis y matiza otras. Monopolio de facto con elevada participación privada frente a monopolio público legal, desintegración horizontal frente a unidad organizativa de correos-telégrafos y teléfonos e integración vertical entre servicio e industria configuran las peculiaridades del modelo español. Todo ello se desenvuelve en una España sometida a un régimen dictatorial, responsable sucesivamente de la autarquía, con salarios y precios controlados y mercados de capital estrechos, y de una estabilización previa a la aplicación de políticas desarrollistas, frente a la Europa democrática del Plan Marshall y de la edad de oro del sistema capitalista.

Lo que aquí ha centrado la atención ha sido el análisis de un sector regulado cuyos precios, fijados por el regulador, repercuten sobre los factores de oferta y demanda, que, a su vez, no son determinados de forma independiente. Los datos empíricos han desvelado el complejo juego de interrelaciones, papel regulador del Estado - política económica- estrategias sectoriales durante los años a caballo entre la autarquía y los albores del crecimiento económico. El análisis resalta la subordinación - tan sólo atenuada por el poder de negociación del sector- de los intereses empresariales a los dictados del régimen franquista, aislado internacionalmente y preocupado por encima de todo por la propia estabilidad del régimen.

El balance final que dimana del análisis del impacto de la regulación económica sobre el servicio telefónico español resulta un tanto paradójico. El contrato entre el Estado y CTNE - auténtico instrumento regulador-pesó como una losa sobre el comportamiento del sector, obstaculizando en ocasiones soluciones más audaces propuestas por la compañía. Para empezar

77 Se preveían en medio año 2.000 cabinas de teléfonos públicos en barrios periféricos para contrarrestar los efectos negativos de las nuevas cuotas de instalación: 10 de noviembre de 1965. El Banco Mundial recomendaba la aplicación de precios reales en los servicios públicos: Presidencia del Gobierno (1967, p. 107).

${ }^{78}$ En palabras del nuevo presidente, «entre la compañía y la delegación del Gobierno no existirán nunca secretos ni barreras», sino cordialidad y recíproca confianza: 10 y 24 de noviembre y 22 de diciembre de 1965. 
por un aspecto positivo, el tamaño de la red creció de forma intensa, con tasas generalmente más altas que las de los países nórdicos y asimilables a las del sur de Europa. Desde el lado negativo, la demanda insatisfecha fue en aumento (salvo en los años inmediatamente posteriores al Plan de Estabilización) y, muy en especial, desde 1962, una vez superada la corta recesión provocada por dicho Plan. En términos comparativos con Europa y redimensionados al tamaño de la red, España, con un 18,81 por cien de peticiones pendientes sobre los teléfonos existentes, se alineaba en el grupo de países con un elevado porcentaje de solicitudes desatendidas, entre ellos Hungría, alejada de los pésimos resultados de otros países del Sur de Europa - Grecia (27 por cien) y Turquía (42 por cien) — y de los óptimos de los nórdicos (porcentajes inferiores a 1 por cien). Pese al aumento de la teledensidad, en lugar de converger, España se fue alejando de los países situados en la cabeza, quedándose pegada a economías poco desarrolladas del Sur y Este de Europa, como Portugal y Polonia. En lo que sí convergió con los países nórdicos fue en el grado de automatización, con porcentajes en torno al 80 por cien, si bien en este caso los puestos de honor correspondían a Holanda y a Gran Bretaña.

Desde el punto de vista de la financiación, en España no fue posible movilizar todos los recursos que las inversiones necesarias para satisfacer las peticiones pendientes requerían y estas inversiones no eran lo suficientemente rentables por la baja utilización de las líneas en funcionamiento y por unas tarifas bajas impuestas desde el Estado. La pobre y desequilibrada — por su concentración en los grandes centros económicos- utilización de la infraestructura telefónica en su conjunto acarreaba una reducida rentabilidad financiera que dificultaba, a su vez, emisiones adicionales de acciones y obligaciones sobre las que fundamentar nuevas inversiones. Unas tarifas reducidas impedían incrementar los recursos de la empresa en un periodo de aumentos en los costes de fabricación. La discriminación de tarifas por tipo de usuario afectó, por otro lado, negativamente a algunos segmentos de mercado. La evolución de la economía española iba transformando un bien de lujo como el teléfono, en un servicio para la empresa.

La pervivencia de una abultada lista de espera a lo largo de todo el periodo privó del servicio a los aspirantes, mientras los abonados perdieron algunas de las ventajas de las externalidades de red al no poder conectar con esos nuevos usuarios potenciales. La brecha territorial no se cerró durante el periodo. En contrapartida, la serie de reajustes llevados a cabo tuvieron un efecto positivo - sin duda, no siempre buscado- al incrementar la eficiencia en el funcionamiento de la red existente. La mayor probabilidad de crecimiento y la demanda de servicio a partir de 1959-1961 alentaron innovaciones organizativas y planes de expansión, sin que se llegara, con todo, a adoptar políticas más ambiciosas reclamadas por algunos. Cabe destacar la adopción de mecanismos más eficientes para gestionar el servicio telefónico y para evitar sobredimensionamientos parciales, así como medidas 
para un uso más intensivo de la red existente. Éstos, a su vez, volvieron a plantear nuevos retos al sector y al sistema regulador, reproduciendo una trayectoria circular.

\section{FUENTES}

Libros de Actas del Consejo de Administración (LACA), Madrid: Archivo de Telefónica. Actas del Consejo de Administración de Standard Eléctrica (ACASTE), Madrid: Archivo de Alcatel-España.

\section{BIBLIOGRAFÍA}

Acemoglu, D., et al. (2006): «Markets versus Governments: Political Economy of Mechanisms». MIT Department of Economics Working Paper, pp. 6-9.

Álvaro, A. (2007): «Redes empresariales, inversión directa extranjera y monopolio: el caso de Telefónica, 1924-1965». Revista de Historia Industrial, 2, pp. 65-96.

Areilza, J. M. (1940): Problemas técnicos de la nueva ordenación de España, Barcelona: Universidad.

ATT (1914): Annual Report 1913, New York.

BANCO DE EsPaÑa (1962): Informe sobre la evolución de la economía española en 1961, Madrid: Banco de España.

BAUDRIER, A. (2001): «Independent regulation and telecommunications performance in developing countries». Conferencia Anual ISNIE, Berkeley, septiembre.

BARrera, E., y SAN Román, E. (2000): «Juan Antonio Suanzes, adalid de la industrialización», en A. Gómez Mendoza (ed.) (2000): pp. 35-68.

BeL, G. (comp.) (1996): Privatización, desregulación y ¿competencia?, Madrid: Civitas.

BogaERTS, R. F. (1963): «Probable evolution of telephony». Electrical Communication, 38, pp. 184-195.

BORDERÍAs, C. (1993): Entre líneas, Barcelona: Icaria.

Brock, G. W. (1995): Toward a Competitive Telecommunication industry, Hillsdale, N. J.: Lawrence Erlbaum.

Calvo, A. (2006): «Telefónica toma el mando: Monopolio privado, expansión y modernización de la telefonía en España, 1924-1945». Revista de Historia Industrial, 32, pp. 67-96.

- (2008): «State, firms and technology. The Rise of Multinational Firms in the Telecommunications: ITT and Compañía Telefónica Nacional de España, 19241945». Bussiness History, 50 (4), pp. 455-473.

- (2009): «Estado, empresa, mercado. Standard Eléctrica y la fabricación de equipo telefónico en España, 1877-1952». Investigaciones de Historia Económica, 13, pp. 43-72.

CARBAllo, R. (1975): Análisis histórico-estructural del sector telefónico en España (19241972), tesis doctoral inédita, Madrid: Universidad Complutense.

CARreras, A. (2007): «Les services dans l'histoire économique», en H.-J. Gilomen (ed.), Les services. Essor et transformation du secteur tertiaire, Zurich: Chronos, pp. 25-38.

CARreras, A., y TAFunell, X. (coords.) (2005): Estadísticas Históricas de España, siglos XIX y XX, Bilbao: Fundación BBVA.

CATALAN, J. (1995): La economía española y la segunda guerra mundial, Barcelona: Ariel. 
CCITT (1964): National Automatic Networks, Ginebra: ITU.

Chapuis, R., y Joel, A. E. (2005): 100 Years of Telephone Switching, Amsterdam: IOS Press.

Crew, M. A., y PARKer, D. (2006): International Handbook on Economic Regulation, Cheltenham: E. Elgar.

CTNE (1946): Bases del contrato con el Estado.

CUADRADO, J. R. (2001): «Los servicios y la industria». Revista de Historia Industrial, 1920, pp. 357-364.

DAVID, P. A. (1992): «Information Network Economics. Externalities, Innovation and Evolution», en C. ANTONELli (ed.), The Economics of Information Networks, Amsterdam: Elsevier Science of Publishers, pp. 103-105.

- (2006): «Economic policy and the Internet: coming to terms with a telecommunication anomaly». Stanford Economic Working Papers, 06-004.

Deloraine, M. (1969): "Tráfico telefónico, telegráfico y télex». Comunicaciones Eléctricas, 44 (1), pp. 3-14.

Dudley, L. (1999): «Communications and Economic Growth». European Economic Review, 43, pp. 595-619.

FERNÁNDEZ, P., y Rose, M. (en prensa): Innovation and Networks in Entrepreneurship in Europe, Oxford: Routledge.

FISCHER, C. S. (1992): America calling: The social history of the telephone in America, Berkeley: University of California Press.

ForEMAN-PECK, J., y MULlER, J. (1988): European telecommunication organisations, Baden-Baden: Nomos.

Fraile, P. (1998): La retórica contra la competencia en España (1875-1975), Madrid: Fundación Argentaria.

García Delgado, J. L. (1987): «La industrialización y el desarrollo económico de España durante el franquismo», en J. NADAL, A. CARRERAS y C. SUdRIÀ (comps.), La economía española en el siglo XX. Una perspectiva histórica, Barcelona: Ariel, pp. 164-189.

GARRUÉS, J., y LóPEz, S. (2008): «Las eléctricas españolas ante la regulación tradicional». Jornadas de Historia de la Electridad, Barcelona, 15-16 de mayo.

GIL, O. (2002): Telecomunicaciones y política en Estados Unidos y España (1875-2002), Madrid: CIS.

Gómez Mendoza, A. (1994): El «Gibraltar económico»: Franco y Riotinto, 1936-1954, Madrid: Río Tinto Minera.

- (ed.) (2000): De mitos y milagros, Barcelona: Universidad.

GutiÉRREZ, J. (2007): "Proceso de integración de las redes telefónicas de San Sebastián y Guipúzcoa en la CTNE». Cuadernos de Historia Contemporánea, 29, pp. 75-94.

HARDY, D. et al. (2002): Networks: Internet, Telephony, Multimedia: Convergences and Complementarities, París: De Boeck Université.

HAYWARD, J. E. (1995): Industrial Enterprise and European Integration: From National to International Champions in Western Europe, Oxford: Oxford University Press.

HerranZ, A. (2007): "Infrastructure Investment and Spanish Economic Growth (18501935)». Explorations in Economic History, 44 (3), pp. 452-468.

HiLls, J. (1984): Information Technology and Industrial Policy, London: Croom Helm. Hulsink, W. (2002): Privatisation and Liberalisation in European Telecommunications, London: Routledge.

ITT LABORATORIES OF SPAIN (1973): Telecommunication planning. Rates and tariffs, Madrid: Héroes.

KAHN, A. E. (1988): The Economics of Regulation Principles and Institutions, Cambridge: MIT Press. 
KrantZ, O. (2000): «The Transport and Telecommunication Sector in Economic Development: Views from the Historical National Accounts». Scandinavian Economic History, 48, pp. 5-29.

LAFOnT, J. J., y Tirole, J. (2001): Competition in Telecommunications, Cambridge, Mass.: MIT Press.

LÓPEZ, S. (2001): «Redes de telecomunicación en el último cuarto del siglo xx: una aproximación bibliográfica». Transportes, Servicios y Telecomunicaciones, 1, pp. 159-168.

- (2003): «The Role of Telefonica: The Internationalization of Telecommunications in Spain, 1970-2000». Business and Economic History On-line, vol. 1.

MaJone, G. (ed.) (1996): Regulating Europe, London: Routledge.

Millward, R. (2005): Private and Public Enterprise in Europe. Energy, Telecommunications and Transport, 1830-1990, Cambridge: CUP, pp. 244-266.

MOKYR, J. (1997): "Are we living in the middle of an Industrial Revolution?». Economic Review, Federal Reserve Bank of Kansas City, pp. 31-43.

NEW (2000): Economy Task Force Report: Making the New Economy Grow: Progressive Policy Institute.

NoAm, M. E. (1990): «The Historic Evolution of the Network System: Past Change, Present Impact, and Future Police», en S. Schaff (ed.), Legal and Economic Aspects of Telecommunication, Elsevier S. P.: North Holland, pp. 461-462.

Noll, R. G. (2000): «Telecommunications Reform in Developing Countries», en A. O. Krueger: Economic Policy Reform: The Second Stage, Chicago y London: University of Chicago Press.

Pascual, P., y Nadal, J. (2008): El coure. I. Producció a l'era industrial, Les Masies de Voltregà: Eumo/La Farga Group.

Plaza, C. (1989): «La Compañía Telefónica». Papeles de Economía Española, 38, pp. 390-408.

Presidencia del Gobierno (1967): II Plan de Desarrollo Económico y Social, Madrid: Imprenta BOE.

PuEYo, J. (2008): «Las relaciones entre las empresas eléctricas y el Estado franquista». Jornadas de Historia de la Electricidad, Centre d'Estudis «Antoni de Capmany»(UB), Barcelona, 15-16 mayo, p. 2.

RÖLlER, L. H., y WAVERMANN, L. (2001): «Telecommunications infrastructure and Economic Development: A Simultaneous Approach». The American Economic Review, 91 (4), pp. 909-923.

Ros, J. et al. (1973): Capitalismo español: de la autarquía a la estabilización, Madrid: Cuadernos para el Diálogo.

Shleifer, A., y Vishny, R. (1998): The Grabbing Hand. Power Pathologies and their Cure, Cambridge y London: Harvard U. P.

Stern, J., y Trillas, F. (2001): «Telecom Regulation: Lessons from independent central Bank». Business Strategy Review, 12 (4), pp. 17-28.

Tamames, R. (1976): La República. La era de Franco, Madrid: Alianza.

TORTElla, G. (1994): El desarrollo de la España contemporánea, Madrid: Alianza.

URI, N. D. (2004): The Economics of Telecommunications Systems, Hauppauge, N.Y.: Nova Science.

VELARDE, J. (1975): «Las inversiones privadas extranjeras en España en el periodo 19601970». Boletín de Estudios Económicos, XXX, pp. 911-930. 